\title{
Awareness and Beliefs on Preconception Health Care Among Women Attending Maternal \& Child Health Services at Moi Teaching and Referral Hospital in Eldoret, Kenya
}

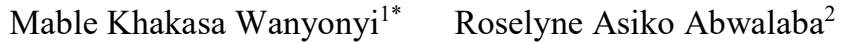 \\ 1.School of Nursing, Department of Reproductive Health, Midwifery and Child Health, Masinde Muliro \\ University of Science and Technology,P.O box 50100-190 kakamega ,Kenya. \\ 2.School of Nursing Department of clinical Nursing and Health informatics Masinde Muliro University of \\ Science and Technology ,P.O box 50100-190 kakamega ,Kenya.
}

\begin{abstract}
Preconception health care is the care given to women for optimal health before pregnancy in order to reduce risk factors and improve pregnancy outcomes. Since the introduction of preconception health care through safe motherhood initiative, little is known about its existence in health care settings in Kenya yet adverse birth outcomes that may be prevented through preconception health are still prevalent. This study aimed at assessing the level of awareness and beliefs on the concept of preconception health care among women attending Maternal Child Health $\&$ family planning services at Moi Teaching and Referral Hospital (MTRH) Structured questionnaires and a Likert scale were used to collect the data from a sample of 384 women attending Maternal Child Health \& family planning services at MTRH. The data was then analyzed quantitatively using the Statistical Package for Social Scientists (SPSS) program to obtain descriptive statistics and results tabulated using charts. The study established that majority of women $(83 \%)$ are not aware of preconception health care services and therefore have not been seeking for the services. Most women agreed with the positive beliefs that a woman should be in good health before becoming pregnant $(96.1 \%)$ The study recommends the need to create awareness so that women of reproductive age are able to know and seek for preconception health care services and Preconception health care clinics to be established within the maternal child health and family planning services to address risks that may impact negatively on pregnancy outcome.
\end{abstract}

Keywords: Awareness, Beliefs, Maternal Child Health Services, Preconception Health care.

DOI: $10.7176 / \mathrm{JHMN} / 60-11$

Publication date:March $31^{\text {st }} 2019$

\section{Introduction and background information}

Preconception care is a set of interventions that identify and modify biomedical, behavioral and social risks to a woman's health and future pregnancies (Elsinga et al, 2008). Preconception care includes both prevention and management strategies emphasizing health issues that require action before conception for maximal maternal and newborn health outcomes. Preconception health care, a long established concept for primary prevention of maternal and perinatal morbidity and mortality through detection and reduction of modifiable risks has been widely propagated for the last decades (De weerd et al, 2008). The notion of preconception care can be found in various global policy and practice recommendations concerning women's health and child survival. The incorporation of various preconception strategies and ideologies within international maternal and child health programs and policies, as far as 30 years back, indicate long term recognition of the importance of such interventions as a means of optimizing pregnancy outcomes (Elsinga et al, 2008).

Several studies have been done regarding the concept of preconception care that reveal knowledge, beliefs and practises towards this service. In a study to determine knowledge and attitudes regarding preconception care in a low income Mexican American population, Coonrod, Bruce, Malcom, Drachman, Frey (2008) found that 89\% of women agreed that improving preconception health benefits pregnancy outcomes. $79 \%$ percent expressed some interest in preconception health care with the obstetrics gynecology office at the preferred location. The average knowledge of preconception care was $76 \%$. The areas of higher knowledge included the effects on pregnancy of folic acid, alcohol use, substance use and verbal, physical and sexual abuse. The conclusion by Coonrod et al (2008) was that there was interest in preconception education and agreement that preconception health has a positive effect on pregnancy.

In a study on preconception care among Oklahoma women by Oklahoma Pregnancy Risk Assessment

Monitoring system, few women, (13.5\%) in Oklahoma received any kind of advice or counselling to prepare for becoming pregnant. The majority of women did not receive any preconception counselling (86.5\%). Those most likely to receive preconception counselling were 25 to 29 years of age, had some college education, health insurance, an intended pregnancy, and were married. Women who did not receive any type of preconception counselling were more likely to smoke and were less likely to take multivitamins in the months prior to pregnancy (CDC, 2006). 
In another study done by Cynthia, Diane and Carol (2009) on preconception health and health care among Utah women, Utah Behavioral Risk Factors Surveillance System data of 2006 indicated the prevalence rates of other high risk conditions among Utah women of childbearing age (18-49) that could also affect preconception health and therefore pregnancy outcomes. Diabetes 1.7\%, heart disease 2.0\% and Asthma 10.6\%. Prevalence of health risks and modifiable behaviors that are known to affect pregnancy outcomes among Utah women were as follows; Overweight $22.4 \%$, obesity $13.9 \%$, tobacco use in the three months before pregnancy $12.1 \%$, alcohol use in the three months before pregnancy $21.9 \%$ and $47.6 \%$ did not take daily multivitamins with folic acid. Conclusions drawn from this study indicated that despite the abundance of public published research about the importance of preconception care, only $33.4 \%$ of Utah women who delivered a live birth during the years 20042006 reported a preconception visit with their health provider.

Keith and Julia (2006) in their study on 'what women know and believe about preconception health care' revealed that $98.6 \%$ of women do understand the importance of optimizing their health prior to pregnancy and realized that the best time to receive information on preconception health is before pregnancy. $95 \%$ preferred to receive information about preconception health from their primary care physicians. Only $39.8 \%$ of women could recall their physicians ever discussing this topic of preconception care. In the same study, participants demonstrated deficiencies in their knowledge of risk factors that impact on maternal and fetal health suggesting that physicians were not addressing preconception health care during routine care.

A study by Inyangala (2008) on birth preparedness and pregnancy outcome in Kakamega district, Kenya, there was no single respondent out of the interviewed women who had attended preconception counselling or risk assessment before becoming pregnant. Inyangala (2008) also reported that most pregnancies were not planned but just happened. In the same study, health workers responded that preconception preparedness was non-existent as they always encountered clients who were already pregnant

Programs and guidelines may vary in response to local needs but the overarching concept of preconception care is present among both industrialized and developing countries (Curtis, 2008). However, it has been observed that in developing countries most providers do not provide this type of care and most consumers are not aware of it (Howse, 2008). In Kenya the concept of preconception health care can be traced back from 1996 as part of the components of reproductive health programmes (MOH, 1996). In 2003 the division of reproductive health of Kenya expanded the four pillars of safe motherhood namely; essential obstetric care, clean and safe delivery, focused antenatal care, and family planning to eight pillars to incorporate post abortion care, targeted post partum care, neonatal care, preconception health care and Prevention of Mother to Child Transmission (PMTCT. At the Moi Teaching and Refferal Hospital, an estimated 21,602 women of reproductive age seek reproductive health services at the hospital per year (Records and Registry data, 2009). Family planning clinic (3,092), ante-natal clinic $(13,322)$, well child clinic $(5187)$ and post-delivery clients $(5,252)$. However Little is known about preconception health care services at the hospital.

Preconception health care is justified as most women do not initiate prenatal care early enough to prevent a number of serious maternal and child health problems. Also, the fetus is most susceptible to developing certain problems in the first 2-10 weeks after conception before prenatal care is normally initiated (Gottesman, 2004). Indeed many women are not aware that they are pregnant until after this critical period. Therefore, they are unable to reduce the risks to their own health and that of their baby unless intervention begins before conception. It is not yet known why most of the women do not attend to such maternal services despite the known benefits. Previous studies like one done by Inyangala (2008), in Kakamega, reveal that most women failed to attend to preconception care without documenting any reasons as to why. Perhaps it could be attributed to lack of awareness, cultural beliefs, taboos, negative perceptions towards care givers, fear of knowing their health status, cost of care, among other reasons.

\section{Statement of the research Problem}

Preconception health care is an important component of Safe Motherhood Initiative to improve maternal and fetal outcomes in pregnancy. However little is known about its existence in the current reproductive health services offered in Maternal Child Health and family planning clinics in Kenya

Adverse pregnancy outcomes that can be reduced or eliminated such as prematurity, congenital birth defects and low birth weight remain a prevalent health problem in Kenya (Simiyu 2004). In the year 2009, of the total (1253) admissions in the newborn unit at MTRH, four hundred an eighty four (38.6)\% were preterm deliveries, thirty seven ( 2.9$) \%$ had neural tube defects, sixty five $(5.2) \%$ had low birth weight, twenty eight $(2.2) \%$ were macrosomic and eighty one (6.5)\% had either single or multiple congenital abnormalities (Records and registry office MTRH 2009). At the same time Ayaya et al (2001) points out that low birth weight neonates account for $11 \%$ of all deliveries. This constitutes $60 \%$ of the admissions at Kenyatta National Hospital and $37 \%$ of all admissions at Moi Teaching and Referral Hospital (MTRH). Most of these complications mentioned above are attributed to nutritional problems, poor management of maternal chronic illnesses, risky behaviors such as smoking, alcohol and drug use as well as untreated sexually transmitted infections during the pre-pregnancy and pregnancy 
period. . Results from this study will therefore reveal potential knowledge gaps and the need for awareness campaigns to improve knowledge and the practises of reproductive women concerning preconception care aimed at reducing adverse pregnancy outcomes.

\subsection{Objectives of the study}

The broad objective of this study was to describe women's awareness, practices and beliefs on the concept of preconception health care.

\section{Specific objectives}

Specific objectives of the study were formulated as follows:

1. To assess the level of awareness of the concept of preconception health care among women attending Maternal Child Health\& family planning services at MTRH.

2. To describe the health seeking behavior for preconception health care among women attending Maternal Child Health\& family planning services at MTRH.

3. To describe the beliefs about preconception health care among women attending Maternal Child Health\& family planning services at MTRH.

4. To determine whether preconception health care services exist at MTRH MCH/FP services.

\section{Research Questions}

The study focused on the following research questions.

1. What is the level of awareness on the concept of preconception health care among women seeking Maternal Child Health \&family planning services at MTRH?

2. Do women seeking Maternal Child Health \&family planning services at MTRH seek for preconception health care services?

3. What are the beliefs about preconception health care among women attending Maternal Child Health \& family planning services at MTRH?

4. Do preconception health care services exist at MTRH, MCH/FP services?

\subsection{Methodology}

\subsection{Study Design}

This was a cross-sectional descriptive study

\subsection{Research site}

The study was conducted in Moi Teaching and Referral Hospital (MTRH). The hospital is located in Uasin Gishu County along Nandi Road 1 kilometer from Eldoret town Kenya. It offers both in-patient and out-patient services and serves as a major referral hospital in Western Kenya. The hospital offers a variety of services including Maternal Child Health and Family planning.. The study was conducted specifically at sites offering reproductive health services or maternal child health services to include antenatal ward \& clinics, family planning clinic, well child clinic and postnatal wards

\subsection{Study population}

The study population consisted of women attending reproductive health services at the Moi Teaching and Referral Hospital. An estimate of 21,602 women of reproductive age seek reproductive health services at MTRH per year (Records and Registry data, 2009). Family planning clinic (3,092), ante-natal clinic $(13,322)$, well child clinic (5187) and post-delivery clients $(5,252)$.

\section{Sample and sampling technique Sample size}

The sample size was determined as follows: $\quad \mathrm{n}=\frac{\mathrm{z}^{2}(\mathrm{pq})}{\mathrm{d}^{2}}$

Where: $\mathrm{n}=$ the desired sample size (if the target population is greater than 10,000 ).

$\mathrm{z}=$ the standard normal deviation at the required confidence interval. At $95 \%$ confidence interval, $\mathrm{z}$ score $=1.96$.

$\mathrm{p}=$ the proportion in the target population estimated to have characteristics being measured in this case, knowledge on preconception health care among women". Since the prevalence is unknown, $50 \%$ was given to give maximum variability and maximum sample size.

$\mathrm{q}=1-\mathrm{p}=1-0.5$

$\mathrm{d}=$ absolute precision size at $5 \%$ level of significance i.e. 0.05

Therefore $\mathrm{n}=\frac{1.96^{2}(0.5 \times 0.5)}{0.05^{2}}=\mathbf{3 8 4}$

A total of 384 women were interviewed. 


\subsection{Sampling}

This study used stratified systematic sampling technique. Stratified sampling was used to group the respondents into homogeneous subsets. These included antenatal mothers, mothers/ women seeking family planning methods, mothers who had brought their babies for immunization and post natal mothers. This was to ensure that women of reproductive age from various categories were represented. The following data on attendance in the previous three months in each stratum was collected to guide the technique for sampling by getting the sampling frame since the population under study was dynamic.

\section{Table 1: Table for sampling}

\begin{tabular}{|l|l|l|l|l|l|l|}
\hline strata & MAY & JUNE & JULY & Average/pm & Per 2weeks & Kth value \\
\hline antenatal & 1011 & 1032 & 950 & $2993 / 3=997$ & $(997 / 4) * 2=548$ & $500 / 134=3.7=4$ th \\
\hline Child clinic & 665 & 686 & 732 & $2083 / 3=694$ & $(694 / 4) * 2=347$ & $300 / 100=3 \mathrm{rd}$ \\
\hline Family planning & 248 & 176 & 152 & $576 / 3=192$ & $(192 / 4) * 2=96$ & $100 / 50=2$ nd \\
\hline postnatal & 620 & 594 & 632 & $1846 / 3=615$ & $(615 / 4) * 2=307$ & $300 / 100=3 \mathrm{rd}$ \\
\hline
\end{tabular}

\subsection{Inclusion criteria}

Women aged between (18-49) years seeking Maternal Child Health and Family Planning services at Moi Teaching and Referral Hospital were included in the study.

\subsection{Exclusion criteria}

Women who met the inclusion criteria but were too ill to participate at the time of data collection were excluded from the study.

\subsection{Research instruments}

The research instruments were made by the researcher with the guidance from the supervisors .A structured questionnaire was used to collect data on awareness, practices and beliefs about preconception health care. An observational checklist was used to ascertain whether preconception health care services exist at Moi teaching and referral Hospital Eldoret. A three point Likert scale was used with response options of, agree, uncertain, or disagree. Content validity of the questionnaire was ascertained by an obstetrician, midwife and the supervisors to ensure that the tool truly measured the knowledge, practices and beliefs about preconception health care. The tools were pre-tested at Uasin Gishu district hospital using 30 women attending reproductive health services. The aim was to ensure that any anomalies of the instruments were revised and the time needed for each respondent estimated.

\subsection{Data collection}

Data was collected for 2 weeks from first week of august 2011 in each stratum. An extension beyond two weeks in each stratum was to be considered if the required sample size was not achieved by the end of the two weeks. Out of the sample size of 384 women, 100 were from postnatal ward, 50 from the family planning clinic, 134 from antenatal clinic and 100 from well child clinic. The numbers in each category was based on the previous attendance. Data collected included:

- Demographic data including age, parity, residence, level of education, religion, marital status; past history of the client to include past medical, obstetric \& gynecological history and family history; gestational age at first antenatal visit (if ever pregnant or was pregnant) and pregnancy planning (at the correct time), planned but (not at the correct time) or unplanned.

- Personal awareness, practices, values and beliefs on preconception health care.

- Preconception services offered at MTRH. An observational checklist was used by looking at the existing records at the $\mathrm{MCH} / \mathrm{FP}$ to see whether the services offered and recorded included preconception health care services.

\subsection{Data Analysis}

Data collected was analyzed quantitatively using the Statistical Package for Social Scientists (SPSS) program. All the completed questionnaires were put into a database and cleaned. The questions and responses were then coded. The proportions and frequencies of the study participants on specific responses stated were computed. These were then tabulated or presented in bar charts or pie charts for illustration. Descriptive statistics such as mean, standard deviation, median and range were used for the continuous variables like age, while frequency listings were used for categorical variables like marital status

\subsubsection{Ethical Considerations}

Approval to conduct the study was obtained from the hospital management and the Institutional of Research and Ethics Committee (IREC) of the School of Medicine, Moi University. Participants were asked to sign an informed consent before participating in the study. Objectives of the study were clear and participation was strictly on voluntary basis. Privacy and confidentiality was assured at all times where by all arrangements were made at the 
various locations mentioned above for privacy where a special room was identified where women sampled for the study were interviewed. Anonymity of the participants was assured by ensuring that their names do not appear in any report. The data collected was under key and lock for safe custody.

\subsubsection{Limitation of the study}

The sampling frame consisted of women seeking maternal child health and family planning services at MTRH therefore cannot be generalized to other populations.

\subsection{Results}

4.1Socio-Demographic Characteristics

The socio-demographic characteristic of the sampled population interviewed is depicted in table1 below. This table indicates the frequency and percentages of the age, marital status, occupation, level of education and religious affiliation of the respondents. Of the 384 women studied, $283(73.7 \%)$ were married. Their mean age in years was $25.5 \pm 6.7$. A third of them i.e. $129(33.6 \%)$ were housewives and only $43(11.2 \%)$ had tertiary level of education. Three quarters $287(75 \%)$ were protestants.

Table 2: Socio-demographic characteristics

\begin{tabular}{|l|lc|}
\hline Characteristic & \multicolumn{2}{|l|}{ Number /Percentage } \\
\hline Age (yrs) & \multicolumn{2}{|c|}{} \\
$18-24$ & 197 & $(51.3 \%)$ \\
$25-34$ & 157 & $(40.9 \%)$ \\
$35-49$ & 30 & $(7.8 \%)$ \\
\hline Marital status & & \\
Single & 91 & $(23.7 \%)$ \\
Married & 283 & $(73.7 \%)$ \\
Separated/divorced & 10 & $(2.6 \%)$ \\
\hline Occupation & & \\
Employed & 100 & $(26.0 \%)$ \\
Business women & 71 & $(18.5 \%)$ \\
Housewife & 164 & $(42.7 \%)$ \\
Student & 49 & $(12.8 \%)$ \\
\hline Highest level of education & \multicolumn{2}{|}{} \\
None & 124 & $(32.3 \%)$ \\
Primary & 148 & $(38.5 \%)$ \\
Secondary & 69 & $(18 \%)$ \\
Tertiary level & 27 & $(7 \%)$ \\
University & 16 & $(4.2 \%)$ \\
\hline Religious affiliation & \multicolumn{2}{|}{} \\
Catholic & 92 & $(24 \%)$ \\
Protestant & 287 & $(74.7 \%)$ \\
Muslim & 3 & $(0.8 \%)$ \\
Others & 2 & $(0.5 \%)$ \\
\hline
\end{tabular}

\subsection{Awareness of preconception health care}

Analysis of awareness on the concept of preconception health care is presented in the pie chart shown in figure 1 below. 


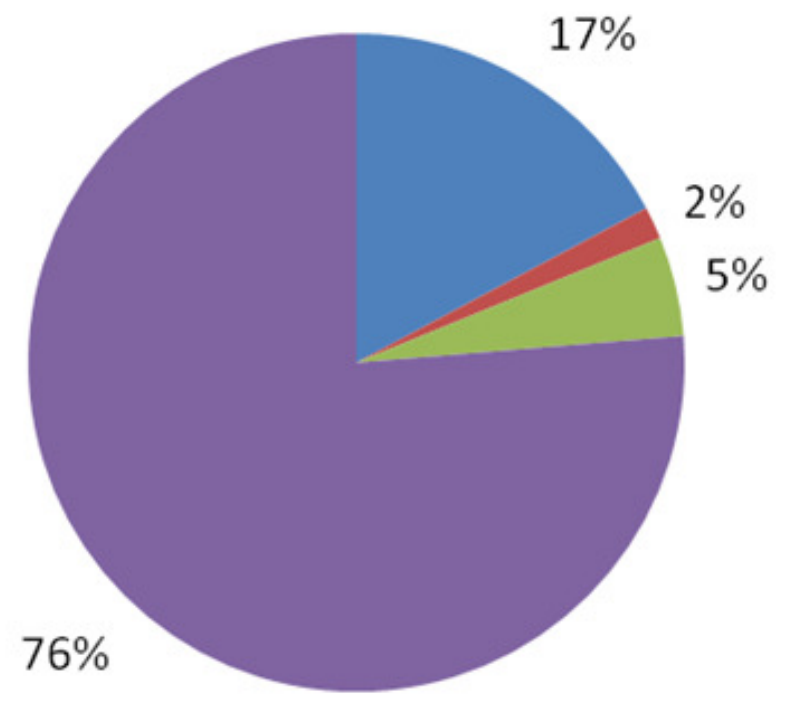

\section{Care given before pregnancy to identify risks and provide intervention}

Any care given to a pregnant woman regardless of the gestation of pregnancy

Same as antenatal care

Don't know

\section{Figure 1: Awareness of preconception healthcare $(\mathrm{N}=384)$}

The study assessed women of reproductive age concerning the level of awareness on preconception health care and revealed that majority of the women interviewed i.e. 319 or $83 \%$ do not know the concept of preconception health care. Of this $83 \%, 5 \%$ thought that preconception care and antenatal care are one and the same. Only 65 respondents representing $17 \%$ were aware of preconception health care. In the same objective women were asked about the importance of a preconception health care visit , 247 (64\%) of the women chose it optimizes the health of the woman before conception, but still 58 (15\%) did not know the importance.

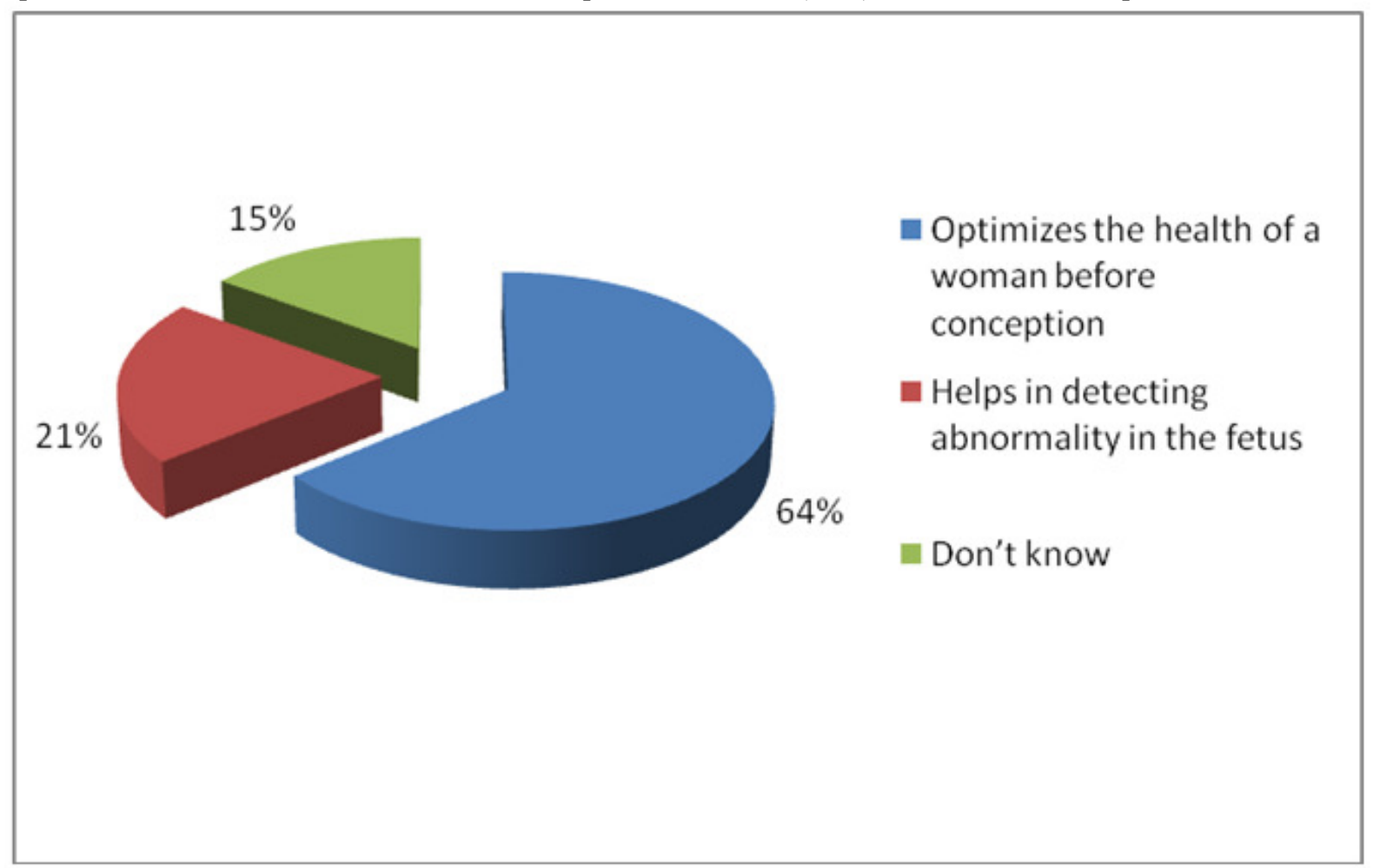

Figure 2: Importance of preconception healthcare visit $(N=384)$

4.3 Preconception health care practices

Preconception health care practices among the interviewees was also evaluated, the results revealed that only 79 $(20.2 \%)$ of the women had been informed by a health care provider about preconception health and $31(8.1 \%) \mathrm{had}$ 
ever sought preconception healthcare services. All those who sought preconception healthcare services i.e. 31 $(100 \%)$ were offered the services that they wanted. Reasons for seeking preconception healthcare services included to know about health status $10(32.3 \%)$ and having had a previous adverse birth outcome $15(48.4 \%)$. For those who had never sought the preconception healthcare services $351(91.4 \%)$, their main reason was that they did not know about it $348(99.1 \%)$.

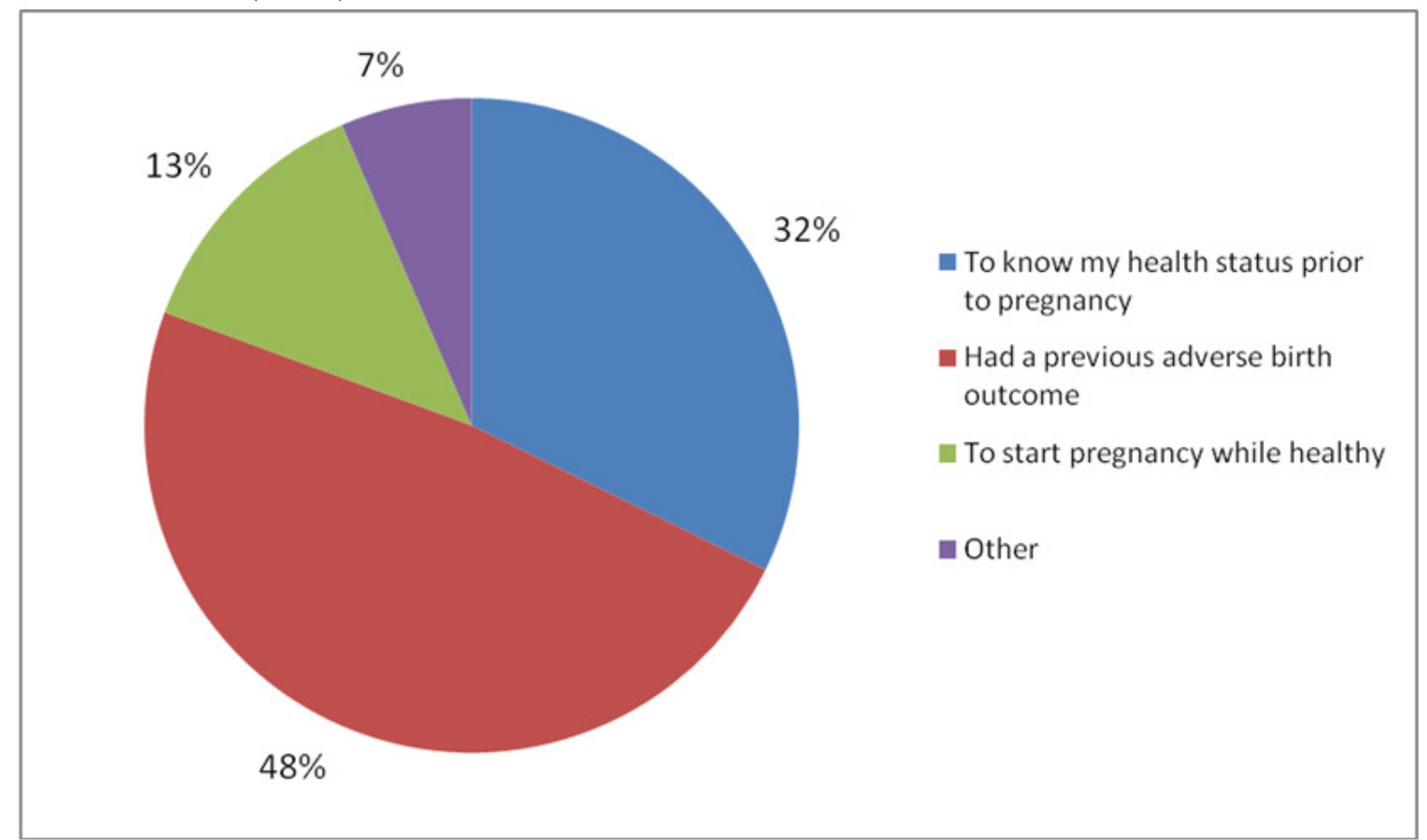

Figure 3: Reasons for seeking preconception healthcare services $(\mathrm{N}=31)$

\subsection{Preconception health care beliefs}

Preconception health care beliefs were also evaluated using the Likert scale. The Likert scale was used to determine whether the beliefs were positive or negative. Proportions of the respondents either agreeing or disagreeing with statements on beliefs were generated.

Table 3: Beliefs about preconception health care $(n=384)$

\begin{tabular}{|l|l|l|l|}
\hline \multicolumn{1}{|c|}{ Preconception healthcare beliefs } & \multicolumn{1}{|c|}{ Agree } & Undecided & Disagree \\
\hline $\begin{array}{l}\text { It is important to be in good health before becoming } \\
\text { pregnant }\end{array}$ & $363(96.1 \%)$ & $3(0.8 \%)$ & $12(3.2 \%)$ \\
\hline Preconception health care improves pregnancy outcomes & $340(88.3 \%)$ & $29(7.7 \%)$ & $15(3.9 \%)$ \\
\hline $\begin{array}{l}\text { Preconception care applies only to women with pregnancy } \\
\text { complications }\end{array}$ & $111(27.2 \%)$ & $35(9.3 \%)$ & $238(63.4 \%)$ \\
\hline Preparing before pregnancy might lead to pregnancy loss & $84(22.2 \%)$ & $14(3.7 \%)$ & $286(74.1 \%)$ \\
\hline Preconception care is not mandatory & $132(34.9 \%)$ & $32(8.5 \%)$ & $220(55.7 \%)$ \\
\hline
\end{tabular}

Both positive and negative beliefs were elicited from the women interviewed. Majority of the women agreed with the positive beliefs that a woman should be in good health before becoming pregnant $(96.1 \%)$ and that preconception healthcare improves pregnancy outcomes (88.3\%) About the negative beliefs most women disagreed that preconception care applies only to women with pregnancy complications $(63.4 \%)$ and that preparing for pregnancy might lead to pregnancy loss (63.4\%). A significant percentage $(34.9 \%)$ of the women believe that preconception health care is not mandatory

\subsection{Existence of preconception health care services at MTRH}

It was found that no records existed to verify whether preconception health care services are offered at the MCH/FP clinics within the hospital as per the observational checklist. Therefore it was difficult to ascertain whether preconception health care services exist at the MTRH 


\subsection{DISCUSSION}

\subsection{Socio-demographic characteristics}

The socio-demographic data revealed that majority of the interviewees were between the ages 18-24, married, housewives, below secondary level of education and majority were also Protestants. The young age with no income and low level of education could have also contributed to knowledge gap on preconception care. The sociodemographic data revealed that majority of the interviewees were between the ages 18-24, married, housewives, below secondary level of education and majority were also Protestants, the young age with no income and low level of education could have influenced the results of this study. From the literature those women who seek for preconception health care services from the studies done were likely to be above 30 years, of higher income and highly educated.(Lois et al 2006;Oklahoma pregnancy risk assessment monitoring system;2006)

\subsection{Awareness of Preconception health care services}

This study assessed women of reproductive age concerning the level of awareness on preconception health care. The results revealed that majority of the women interviewed i.e. 319 or $83 \%$ do not know the concept of preconception health care. Only 65 representing 17\% knew what preconception health care was. These findings indicate that most women of reproductive age are not aware of preconception health care services. This could be attributed to the failure of health care providers to inform women of reproductive age on preconception health care services as they seek for reproductive health services. Unlike in Kenya, a study in America by Conrood (2008) to determine knowledge and attitude regarding preconception care in a low income Mexican American population revealed a higher knowledge of preconception care with an average score of $76 \%$. The higher knowledge on the concept of preconception health care in this study could be attributed to information and awareness among the women studied.

With regard to the importance of preconception health care, majority of the women $(64 \%)$ agreed that it optimizes the health of the woman before conception, Still 5.7\% did not know the importance. Another study by Keith and Julia (2006) on what women know and believe showed that majority of the women $(98.6 \%)$ understood the importance of optimizing their health prior to pregnancy and that the best time to receive information on preconception health is before pregnancy.

\subsection{Seeking of preconception health care services among women of reproductive age}

Only $20.2 \%$ of the women had been informed by a health care provider about preconception health. This clearly shows that health care workers are not addressing and educating women on preconception health care issues. Among those who have been spoken to by health care providers only $8.1 \%$ had ever sought preconception health care services. All those who sought preconception health care services were offered the services that they wanted. This point out clearly that women are given the services only when they ask for them. The main reasons women gave for seeking preconception health care services included to know their health status prior to pregnancy (32\%) and having had a previous adverse birth outcome $(48.4 \%)$. This study also revealed that majority of the women $(91.4 \%)$ never sought for preconception health care services. Their main reason for not seeking preconception health care services was that they did not know about it (99.1\%). According to the health belief model health behavior is determined by personal beliefs or perceptions about a disease or condition and the strategies available to decrease its occurrence, in this case, if women do not know the value of preconception health care, then they are unlikely to seek for the service. This also indicates that health care providers do not initiate and talk to women about preconception health but rather wait for women themselves to ask for the services so that those who are knowledgeable may ask and those who are not knowledgeable will never ask. This results are almost similar to a study done in the US on preconception care among Oklahoma women that revealed few women $(13.5 \%)$ in Oklahoma received any kind of advice or counseling to prepare for becoming pregnant, majority of the women $(86.5 \%)$ did not receive any kind of counseling (Oklahoma Pregnancy Risk Assessment Monitoring System, 2006). In Asia, only 33.4\% of Utah women who delivered a live birth during the years 2004-2006 reported a preconception visit with their health care provider. These results were reported despite the abundance of public published research about the importance of preconception care in Utah. Keith and Julia (2006) also in their study on 'What Women Know and believe about preconception health care' reported that only 39.8\% of the women could recall their physicians ever discussing this topic of preconception care. This result is slightly higher than the results obtained in this study.

\subsection{Beliefs}

Both positive and negative beliefs were elicited from the women interviewed. Majority of the women agreed with the positive beliefs that a woman should be in good health before becoming pregnant and that preconception healthcare improves pregnancy outcomes. This could be attributed to the belief of most women that their health could affect that of the fetus. About the negative beliefs most women disagreed that preconception care applies only to women with pregnancy complications and that preparing for pregnancy might lead to pregnancy loss. A 
significant percentage $(34.9 \%)$ of the women believes that preconception health care is not mandatory. This latter finding may be because health care workers do not talk to the women about the importance of preconception health care. A study in America by Conrood (2008) revealed that most women believed that preconception health has a positive effect on pregnancy.

\subsection{CONCLUSIONS AND RECOMMENDATIONS \\ 6.1 Conclusions}

The study specifically sought to determine awareness, practices and beliefs about preconception health care services and whether such services exist at the hospital. The study established that:

- Majority of women are not aware of preconception health care services and therefore have not been seeking for the services

- . Most obstetricians, midwives and nurses are not addressing preconception health care during routine care and therefore this creates a knowledge gap.

- Majority of the women believe that a woman should be in good health before becoming pregnant and that preconception healthcare improves pregnancy outcomes.

- No records existed to ascertain whether preconception health care services are offered within the maternal child health and family planning services at Moi Teaching and Referral Hospital in Eldoret.

\subsection{Recommendations}

In view of these findings, the study recommended the following:

There is need to create awareness on preconception health care so that women of reproductive age are able to know and seek for preconception health care services

Preconception health care clinics should be established within the maternal child health and family planning services to address risks that may impact negatively on pregnancy outcome and to be accessible to most women in need of the service.

\section{ACKNOWLEDGEMENT}

I would like to thank to my family for moral, financial and material support that enabled me to collect and analyze the data.

\section{References}

1. Berry, R.J (.2000). Prevention of Neural Tube Defects with folic acid in China. England journal of medicine 341(20):1485-1490.

2. Centres for Disease Control and Prevention (CDC) (2006). Agency for Toxic Substances and Disease Registry (ATDSR). Preconception care work group and the select Panel on preconception care: Recommendations to improve preconception health and health care-United States.

3. Curtis, G.M. (2008). Preconception care: A clinical case of "think globally, act locally" American journal of obstetrics and Gynecology. 199(6):257-258.

4. Coonrod, D., Bruce, N., Malcom, T., Drachman, D., and Frey, K. (2008). Knowledge and attitudes regarding preconception care in a predominantly low-income Mexican American population. American journal of Obstetrics and Gynaecology 200(6):686 - 698.

5. De Kock, J and Van der Walt.C. (2004). Maternal and Newborn Care. Juta and Co Ltd Publishers, Lansdowne.

6. De Weerd, S., Wouters, M.G., Boertjens. J., Bos. K.L., and Steeger. E.A. (2002). Preconception Counselling: Evaluation of an outpatient clinic at a University hospital. National. Center for Disease Control and Development, Atlanta, USA.

7. Elsinga, J., Lieke. C., Potjer. J., Karin. M., Cessie. S., Willem. J.J., and Simone. E (2008). The effect of preconception Counselling on lifestyle and other behavior before and during pregnancy. Journal of Womens Health Issues 18(6) 117-125.

8. Fraser, D.M., Cooper, M.A. and Nolte A.W. (2010). Myles Textbook for Midwives. Elsevier Limited, London UK.

9. Gottesman, M.M. (2004). Transforming preconceptional, prenatal and interconceptional care into a comprehensive commitment to women's health. Journal of Paediatric Health Care 18(1): 40-44.

10. Howse, L.J. (2008). Marching forward: Action steps to optimize the health of women and babies. Journal of Women's Health Issues 18(6):10-12.

11. Keith, A. F., and Julia, A.F. (2006). What Women Know and Believe. Maternal Child Health journal 10(5):7377.

12. Kesmodel, U., and Schioler, P. (2002). Drinking during pregnancy; attitudes and knowledge among pregnant Danish women. .Alcohol clinic express 26(10):1553-1560.

13. Ministry of Health (MOH) Kenya. (1996). National Reproductive Health Strategy, 1997-2010. Nairobi. 
14. MTRH (Kenya), 2009. Records and registry data

15. Inyangala, H. (2008). Asurvey on birth preparedness and pregnancy outcome in Kakamega District. Published thesis report, Moi University.

16. Prue, C.E (2006). Formative Research of Child Bearing Age on various preconception health topics. Centres for Disease Control and prevention.Springer, N. (2008).Preconception health care: Journal of Maternal and child health.12(6):774-776.

First A. Mable khakasa Wanyonyi was born on $12^{\text {th }}$ march 1981 in Bungoma county Kenya. Pursued Bachelor of science in Nursing (BSCN) from the University of Nairobi (2000-2005). Master of science in Nursing (Msc) Maternal and Neonatal Health at Moi University 2009-2011. Currently Lecturer at Masinde Muliro University, School of Nursing Kenya. Member of the Nursing Council of Kenya since 2005. Currently pursuing a PHD (Doctor of philosophy in public health ) at Masinde Muliro University of science and Technology

Second A. Roselyne Asiko Abwalaba was born on 26 ${ }^{\text {th }}$ April 1978 in Kakamega County Kenya. She pursued Diploma in Nursing at Kenya medical training college (2006-2009). Bachelor of science in Nursing (2011-2013), and Master of Science in Nursing (paediatrics) (2015-2018) both at Masinde Muliro University, Kenya . On going PHD student at Masinde Muliro University Kenya. Became a member of Nursing Council of Kenya in 2009. 